\title{
Acute Respiratory Tract Infection and 25-Hydroxyvitamin D Concentration: A Systematic Review and Meta-Analysis
}

\author{
Hai Pham ${ }^{1,2, *}$, Aninda Rahman ${ }^{1,2}{ }^{(1)}$, Azam Majidi ${ }^{1,2}$, Mary Waterhouse ${ }^{1}$ and \\ Rachel E. Neale ${ }^{1,2}$ (D) \\ 1 Population Health Department, QIMR Berghofer Medical Research Institute, Herston, QL 4006, Australia \\ 2 School of Public Health, The University of Queensland, Herston, QL 4006, Australia \\ * Correspondence: hai.pham@qimrberghofer.edu.au; Tel.: +61-7-3845-3547
}

Received: 29 July 2019; Accepted: 19 August 2019; Published: 21 August 2019

\begin{abstract}
Observational studies and randomised controlled studies suggest that vitamin D plays a role in the prevention of acute respiratory tract infection (ARTI); however, findings are inconsistent and the optimal serum 25-hydroxyvitamin $\mathrm{D}(25(\mathrm{OH}) \mathrm{D})$ concentration remains unclear. To review the link between 25(OH)D concentration and ARTI, we searched PubMed and EMBASE databases to identify observational studies reporting the association between $25(\mathrm{OH}) \mathrm{D}$ concentration and risk or severity of ARTI. We used random-effects meta-analysis to pool findings across studies. Twenty-four studies were included in the review, 14 were included in the meta-analysis of ARTI risk and five in the meta-analysis of severity. Serum $25(\mathrm{OH}) \mathrm{D}$ concentration was inversely associated with risk and severity of ARTI; pooled odds ratios (95\% confidence interval) were 1.83 (1.42-2.37) and $2.46(1.65-3.66)$, respectively, comparing the lowest with the highest $25(\mathrm{OH}) \mathrm{D}$ category. For each $10 \mathrm{nmol} / \mathrm{L}$ decrease in $25(\mathrm{OH}) \mathrm{D}$ concentration, the odds of ARTI increased by $1.02(0.97-1.07)$. This was a non-linear trend, with the sharpest increase in risk of ARTI occurring at 25(OH)D concentration < $37.5 \mathrm{nmol} / \mathrm{L}$. In conclusion, there is an inverse non-linear association between $25(\mathrm{OH}) \mathrm{D}$ concentration and ARTI.
\end{abstract}

Keywords: respiratory infection; vitamin D; systematic review; observational studies; 25-hydroxyvitamin D; meta-analysis; acute infection

\section{Introduction}

Acute respiratory tract infection (ARTI) is very common, with most people experiencing at least one episode of ARTI each year [1]. ARTI includes upper respiratory tract infection (URTI) and lower respiratory tract infection (LRTI). The common cold and influenza are the most common ARTIs globally; the highest rate occurs during the winter months in temperate areas with little seasonal change in tropical regions [2]. During epidemic months, influenza can affect $20 \%$ to $50 \%$ of people worldwide [2]. Bronchitis and pneumonia are the two most common infections of the lower airways, and mortality due to LRTI is high [3]. In 2015, more than 2.8 million deaths worldwide were due to LRTI; children and the elderly are the most affected groups [3].

Vitamin D is critical for skeletal health and may play a role in other health outcomes, including infection. Vitamin D status is estimated by measuring the serum concentration of 25 -hydroxyvitamin D $(25(\mathrm{OH}) \mathrm{D})$; this varies seasonally and the lowest concentration in the winter/spring months coincides with the highest ARTI incidence, suggesting a link between vitamin D and ARTI [4]. This is supported by laboratory studies demonstrating an important role of vitamin D in the immune system. Vitamin D promotes the elimination of pathogens and suppresses prolonged inflammatory responses [5-7]. 
It enhances the production of antimicrobial peptides such as defensins and cathelicidins, which offer natural protection against microbial pathogens [8].

Many studies have investigated the link between 25(OH)D serum concentration and ARTI and the effect of vitamin D supplementation on ARTI. Two recent meta-analyses of observational studies considered associations between $25(\mathrm{OH}) \mathrm{D}$ concentration and ARTI incidence in children $[9,10]$. One included case-control studies in children aged $\leq 5$ years and found higher odds of $25(\mathrm{OH}) \mathrm{D}$ deficiency in those with LRTI [9]. The other found an inverse association between prenatal maternal $25(\mathrm{OH}) \mathrm{D}$ concentration and risk of ARTI in the offspring [10]. The most recent systematic review and meta-analysis including older children and adults was published in 2015 as a conference abstract only-it included 19 observational studies and found a significant inverse association between 25(OH)D concentration and risk of ARTI [11]. A systematic review of 25 observational studies and 14 randomised-controlled trials (RCTs) was completed in 2013 [12]. It concluded that there was an inverse association between $25(\mathrm{OH}) \mathrm{D}$ concentration and risk of ARTI, but did not include a meta-analysis [12]. Some observational studies have found an inverse link between $25(\mathrm{OH}) \mathrm{D}$ concentration and severity of ARTI, as measured by duration of the illness, hospitalisation and severity index [13-16]; however, there has been no meta-analysis of these findings.

Results from RCTs investigating the effect of vitamin D supplementation on ARTI are inconsistent. Two meta-analyses found a significant benefit of vitamin D supplementation on ARTI $[17,18]$ while another three did not [19-21]. There are indications of a greater protective effect in people with marked vitamin D deficiency [20,22], but the trials were unable to indicate an optimal concentration of 25(OH)D. We therefore conducted a systematic review and meta-analysis of observational studies to evaluate the link between serum 25(OH)D concentration and the risk and severity of ARTI in adolescents and adults. Findings from this meta-analysis will provide insights into the influence of vitamin D on ARTI risk and severity, and give an indication of the optimal $25(\mathrm{OH}) \mathrm{D}$ concentration for ARTI prevention and management.

\section{Materials and Methods}

The study protocol was registered with the PROSPERO International Prospective Register of Systematic Reviews prior to commencement [23].

\subsection{Search and Screening Strategy}

PubMed and EMBASE databases were searched from their inception until 12th June 2019. Keywords were chosen from the Medical Subject Headings (MeSH) terms in PubMed and explosion (exp) of EMTREE terms in EMBASE. Essentially, we searched for the terms "vitamin d" or "25-hydroxyvitamin $\mathrm{D}$ " or " $25 \mathrm{OHD}$ " or " $25(\mathrm{OH}) \mathrm{D}$ " or "hypovitaminosis $\mathrm{D}$ " in combination with "respiratory tract infection*" or "respiratory infectio*" or "respiratory diseas" or "pneumonia" or "influenza" or "bronchiolitis" or "common cold". The complete search strategies are shown in the supplementary material (Supplementary File S1).

All titles, abstracts and full text were independently screened by two investigators, Hai Pham and Aninda Rahman. Any discrepancies were resolved through consultation with Rachel Neale and Mary Waterhouse.

\subsection{Inclusion/Exclusion Criteria}

Inclusion criteria: The eligibility criteria were: (1) observational studies including cohort, case-control and cross-sectional studies; (2) published in English; (3) full text available; (4) reported the association between circulating $25(\mathrm{OH}) \mathrm{D}$ concentration and ARTI risk or severity; (5) the target population was healthy adults or adolescents aged 12 years and older.

Exclusion criteria: Studies investigating the link between 25(OH)D concentration and tuberculosis or chronic lung conditions such as chronic obstructive pulmonary disease and asthma were excluded. 


\subsection{Definition of Outcome}

Primary outcome: The primary outcome was the risk of ARTI, defined as an acute infection of the respiratory tract in either the lower or upper airway or with the location not specified. ARTI was either self-reported via surveys or symptom diaries, or clinically confirmed with or without evidence from X-rays or laboratory tests.

Secondary outcome: The secondary outcome was the severity of ARTI, defined according to the duration of the illness, hospitalisation, admission to an intensive care unit, symptom severity score or index, or mortality.

\subsection{Quality Assessment}

We used the customised Newcastle-Ottawa scale (NOS) to assess the quality of each study [24]. The NOS tools are slightly different for each study design but generally include three main categories, namely: (1) selection of participants; (2) control for confounders; and (3) measurement of exposure or outcome (Supplementary File S2).

\subsection{Statistical Analysis Methods}

We used STATA 13 (StataCorp, College Station, Texas, USA) and SAS 9.4 (SAS Institute Inc., Cary, NC, USA) for statistical analyses. We included studies in the meta-analysis that reported either:

1. A measure of association between $25(\mathrm{OH}) \mathrm{D}$ concentration and ARTI risk or severity (odds ratio $(\mathrm{OR})$, relative risk (RR), hazard ratio (HR), mean difference (MD)) and their $95 \%$ confidence interval (CI) or standard deviation (SD); or

2. Sufficient data to derive two by two tables of ARTI risk, comparing the lowest versus the highest 25(OH)D category.

We included the estimate from the most fully adjusted model for each study in the meta-analysis comparing the risk of ARTI in the lowest versus highest $25(\mathrm{OH}) \mathrm{D}$ category. When a study reported results using different $25(\mathrm{OH}) \mathrm{D}$ thresholds, we used $50 \mathrm{nmol} / \mathrm{L}$ as it was the most commonly used threshold. Two studies reported HRs as the measure of association between $25(\mathrm{OH}) \mathrm{D}$ concentration and risk of ARTI $[25,26]$; we included these two studies in the meta-analysis, considering the HR as an approximation of the OR. A random-effects model was used to pool the results.

We used a method described by Greenland and Longnecker to estimate trends across categories of exposure to calculate the effect of each $10 \mathrm{nmol} / \mathrm{L}$ decrease in $25(\mathrm{OH}) \mathrm{D}$ concentration on the risk of ARTI $[27,28]$. This method estimates the covariances between multivariable-adjusted odds ratios using the number of cases in each exposure category. We used variance least-squares regression to compute the trends in two studies in which the number of cases in each exposure category was not reported $[25,29]$. The representative value for each $25(\mathrm{OH}) \mathrm{D}$ category was assigned using either the midpoint of the range or by subtracting or adding the half width of the adjacent exposure category for open-ended categories [30]. We also used fixed effects to fit a restricted cubic spline model with 3 knots to evaluate a potential non-linear dose-response association between 25(OH)D concentration and ARTI risk [28].

For the overall analysis of severity, we defined a severe ARTI to be one that had a moderate-to-high severity score or resulted in death (no studies based on other severity outcomes were included). We also performed a separate meta-analysis to assess the association between $25(\mathrm{OH}) \mathrm{D}$ concentration (lowest versus highest category) and ARTI mortality.

\subsection{Assessment of Heterogeneity and Publication Bias}

Heterogeneity across studies was assessed using $\mathrm{I}^{2}$ statistics. We conducted meta-analyses comparing the risk of ARTI in the highest versus the lowest $25(\mathrm{OH}) \mathrm{D}$ category stratified by: (i) infection location if reported (URTI or LRTI); (ii) outcome measurement methods (self-reported or clinically confirmed); (iii) mean $25(\mathrm{OH}) \mathrm{D}$ concentration in the study population $(<60 \mathrm{nmol} / \mathrm{L}$ or $\geq 60 \mathrm{nmol} / \mathrm{L}$; 
cut point chosen to maximize the number of studies included in each subgroup); and (iv) factors considered as confounders (fully adjusted model or crude/non-fully adjusted model) to explore potential sources of heterogeneity. We used funnel plots and the Egger test to test for publication bias.

\section{Results}

\subsection{Identification and Selection of Studies}

Figure 1 illustrates the study selection process. The PubMed and EMBASE searches yielded a total of 1589 records after removing duplicates. We screened the full text of 33 studies and excluded nine that did not meet the selection criteria. Of the 24 studies included, 10 reported the association between 25(OH)D and the risk of ARTI [25,29,31-38], eight reported on the severity of ARTI [14,16,39-44], and six reported on both the risk and severity $[13,15,26,45-47]$.

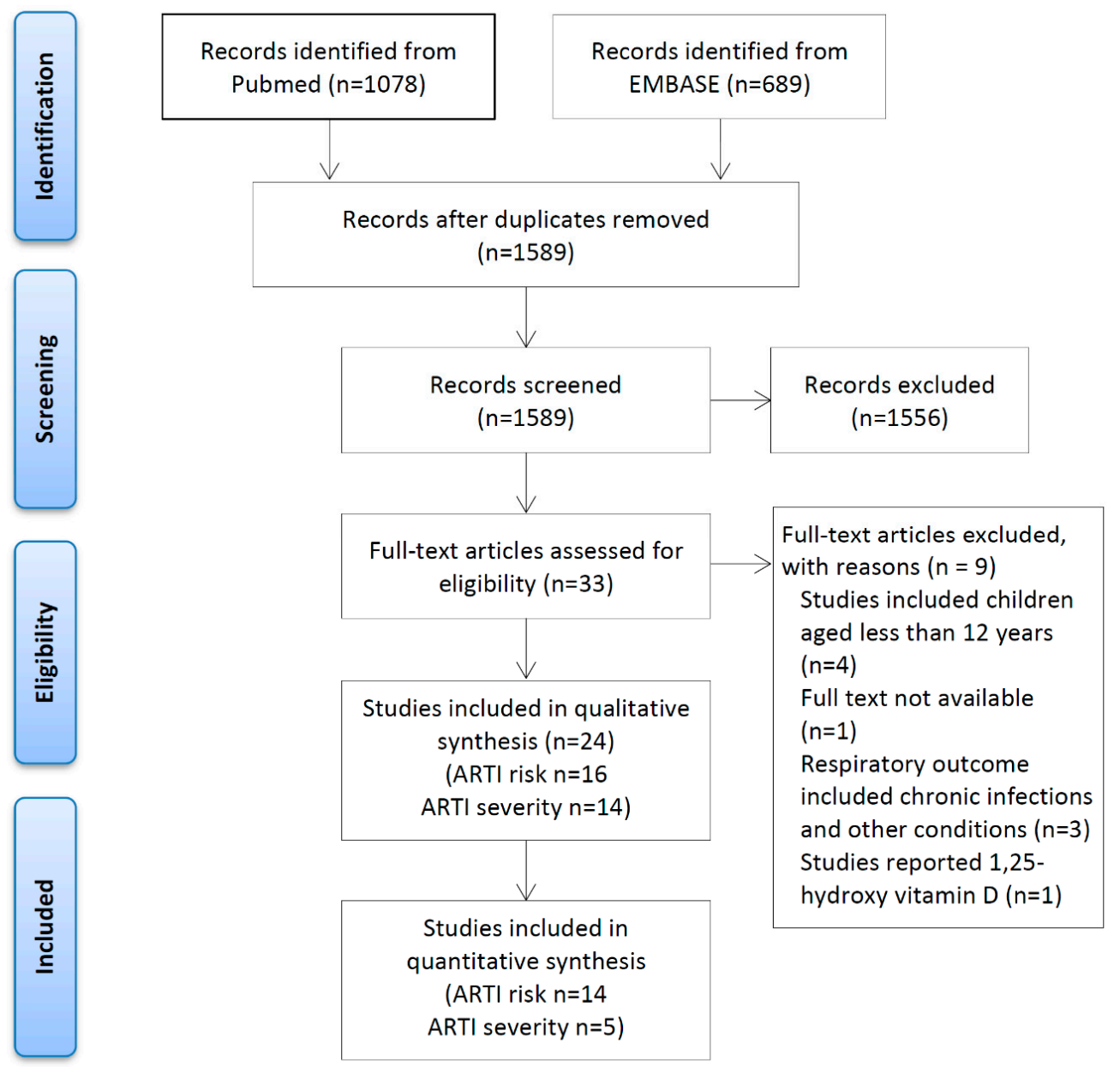

Figure 1. The Prisma flowchart for study selection process. Note: ARTI $=$ acute respiratory tract infection.

\subsection{Study Characteristics}

The characteristics of the included studies are summarised in Tables 1 and 2. There were three case-control studies, 13 cross-sectional studies and eight prospective cohort studies. The relationship between ARTI risk or severity and $25(\mathrm{OH}) \mathrm{D}$ status was reported either by categories of exposure or per unit increase in exposure. The cut point for 25(OH)D categories varied across studies; the upper limit of the lowest category ranged from 25 to $95 \mathrm{nmol} / \mathrm{L}$, and the cut point for the highest category ranged from 25 to $120 \mathrm{nmol} / \mathrm{L}$ (Tables 1 and 2). Serum 25(OH)D concentration was measured using liquid chromatography-mass spectrometry (LCMS) in four studies and non-chromatography assays in 19 studies. One did not specify which method was used to measure $25(\mathrm{OH}) \mathrm{D}$ concentration [44]. 
Table 1. Characteristics of studies reporting the association between risk of acute respiratory tract infection and 25(OH)D concentration.

\begin{tabular}{|c|c|c|c|c|c|c|c|c|c|c|c|}
\hline $\begin{array}{c}\text { First Author } \\
\text { (Publication Year) }\end{array}$ & $\begin{array}{l}\text { Year of } \\
\text { Study }\end{array}$ & $\begin{array}{l}\text { Follow-Up } \\
\text { Time }\end{array}$ & Outcome & Participants & $\begin{array}{c}\text { Age (Mean } \\
\pm \text { SD)/Sex } \\
(\% \text { Female) }\end{array}$ & $\begin{array}{l}\text { Sample } \\
\text { Size }\end{array}$ & $\begin{array}{c}\text { Outcome } \\
\text { Measurement }\end{array}$ & $\begin{array}{c}\text { Mean (SD)/Median } \\
\text { (Q1-Q3) 25(OH)D } \\
\text { (nmol/L) }\end{array}$ & $\begin{array}{l}\text { Lowest } \\
\text { 25(OH)D } \\
\text { Category } \\
\text { (nmol/L) }\end{array}$ & $\begin{array}{l}\text { Highest } \\
\text { 25(OH)D } \\
\text { Category } \\
\text { (nmol/L) }\end{array}$ & $\begin{array}{l}\text { 25(OH)D } \\
\text { Measurement } \\
\text { Method }\end{array}$ \\
\hline \multicolumn{12}{|c|}{ Case-Control Studies } \\
\hline $\begin{array}{l}\text { Jovanovich, A. J. } \\
\text { (2014) [32] }\end{array}$ & 2008-2010 & & Pneumonia & $\begin{array}{l}\text { Cases: patients with CAP } \\
\text { Controls: patients without CAP }\end{array}$ & $\begin{array}{l}\text { Age: } 60 \pm 17 \\
\text { Sex: } 71 \% \mathrm{~F}\end{array}$ & 132 & $\begin{array}{l}\text { Laboratory or x-ray } \\
\text { confirmed }\end{array}$ & $\begin{array}{c}\text { Cases: } 70.1(62.2-79.6) \\
\text { Controls: } 79.3(71.1-88.1)\end{array}$ & 50 & $\geq 50$ & INCSTAR RIA \\
\hline $\begin{array}{l}\text { Nanri, A. (2017) } \\
\text { [35] }\end{array}$ & 2011 & & Influenza & $\begin{array}{l}\text { Cases: employees with influenza } \\
\text { Controls: employees without } \\
\text { influenza }\end{array}$ & $\begin{array}{l}\text { Age: } 38 \pm 12 \\
\text { Sex: } 17 \% \mathrm{~F}\end{array}$ & 532 & $\begin{array}{l}\text { Self-reported } \\
\text { (past } 6 \text { months) }\end{array}$ & $\begin{array}{c}\text { Cases: } 56.1(12.8) \text { Controls: } \\
55.9(13.0)\end{array}$ & 50 & $\geq 75$ & CBP assay \\
\hline $\begin{array}{c}\text { Mamani, M. (2017) } \\
\text { [45] }\end{array}$ & NA & & Pneumonia & $\begin{array}{l}\text { Cases: patients with CAP } \\
\text { Controls: patients' companions }\end{array}$ & $\begin{array}{l}\text { Age: }>18 \\
\text { Sex: } 30 \% \mathrm{~F}\end{array}$ & 149 & $\begin{array}{l}\text { Laboratory or x-ray } \\
\text { confirmed }\end{array}$ & $\begin{array}{c}\text { Cases: } 54.7 \text { (61.9) Controls: } \\
48.1(27.8)\end{array}$ & 25 & $>50$ & Diarosin CLIA \\
\hline $\begin{array}{l}\text { Ginde, A.A. (2009) } \\
\text { [29] }\end{array}$ & 1988-1994 & & URTI & NHANES III (1988-1994) & $\begin{array}{l}\text { Cross-Section } \\
\text { Age: } \geq 12 \\
\text { Sex: } 53 \% \mathrm{~F}\end{array}$ & $\begin{array}{l}\text { al Studies } \\
18,883\end{array}$ & $\begin{array}{l}\text { Self-reported } \\
\text { (past few days) }\end{array}$ & $72.2(52.3-92.1)$ & 25 & $\geq 75$ & Diasorin RIA \\
\hline $\begin{array}{l}\text { Quraishi, S.A. } \\
\text { (2013) [37] }\end{array}$ & 1988-1994 & & Pneumonia & NHANES III (1988-1994) & $\begin{array}{l}\text { Age: } \geq 17 \\
\text { Sex: } 53 \% \mathrm{~F}\end{array}$ & 16,975 & $\begin{array}{l}\text { Self-reported } \\
\text { (past } 12 \text { months) }\end{array}$ & $59.8(44.8-79.7)$ & 25 & $\geq 75$ & Diasorin RIA \\
\hline $\begin{array}{l}\text { Khalid, A.N. (2015) } \\
\text { [33] }\end{array}$ & 2001-2006 & & $\begin{array}{c}\text { Acute } \\
\text { rhinosinusitis }\end{array}$ & $\begin{array}{l}\text { NHANES } \\
\text { 2001-2006 }\end{array}$ & $\begin{array}{l}\text { Age: } \geq 17 \\
\text { Sex: } 51 \% \mathrm{~F}\end{array}$ & 3921 & $\begin{array}{l}\text { Self-reported } \\
\text { (past } 24 \mathrm{~h})\end{array}$ & $54.8(39.8-69.7)$ & 50 & $\geq 50$ & Diasorin RIA \\
\hline $\begin{array}{l}\text { Monlezun, D.J. } \\
\text { (2015) [34] }\end{array}$ & 2001-2006 & & ARTI & NHANES 2001-2006 & $\begin{array}{l}\text { Age: } \geq 17 \\
\text { Sex: } 51 \% \mathrm{~F}\end{array}$ & 14,108 & $\begin{array}{l}\text { Self-reported } \\
\text { (past } 1 \text { month) }\end{array}$ & $52.3(37.4-67.2)$ & 25 & $\geq 75$ & Diasorin RIA \\
\hline $\begin{array}{l}\text { Berry, D.J. (2011) } \\
\text { [31] }\end{array}$ & 2002-2004 & & ARTI & Birth cohort born 1958 & $\begin{array}{l}\text { Age: } 45 \\
\text { Sex: } 50 \% \mathrm{~F}\end{array}$ & 6789 & $\begin{array}{l}\text { Self-reported } \\
\text { (past } 3 \text { weeks) }\end{array}$ & 52.2 & 25 & $\geq 100$ & IDS OCTEIA \\
\hline $\begin{array}{c}\text { Robertsen, S. } \\
\text { (2014) [46] }\end{array}$ & 2007-2008 & & ARTI & Tromsø population-based study & $\begin{array}{l}\text { Age: } \geq 40 \\
\text { Sex: } 57 \% \mathrm{~F}\end{array}$ & 6350 & $\begin{array}{l}\text { Self-reported } \\
\text { (past } 7 \text { days) }\end{array}$ & & NA & NA & Roche CLIA \\
\hline$\underset{[38]}{\text { Rafiq, R. (2018) }}$ & 2008-2012 & & $\begin{array}{l}\text { Common } \\
\text { cold }\end{array}$ & NEO study, BMI $\geq 27 \mathrm{~kg} / \mathrm{m}^{2}$ & $\begin{array}{l}\text { Age: } 45-65 \\
\text { Sex: } 56 \% \mathrm{~F}\end{array}$ & 6138 & $\begin{array}{l}\text { Self-reported } \\
\text { (past } 1 \text { month) }\end{array}$ & 71.3 & 50 & $\geq 75$ & $\begin{array}{l}\text { Diasorin RIA, } \\
\text { IDS CLIA, Roche } \\
\text { CLIA }\end{array}$ \\
\hline Lu, D. (2017) [13] & 2011-2012 & & Pneumonia & Hospitalised patients & $\begin{array}{l}\text { Age: } 60-94 \\
\text { Sex: } 31 \% \mathrm{~F}\end{array}$ & 163 & Clinically diagnosed & $30.0(11.2)$ & 25 & $\geq 25$ & IDS ELISA \\
\hline $\begin{array}{l}\text { Scullion, L. (2018) } \\
\text { [47] }\end{array}$ & NA & & ARTI & Elite rugby players and rowers & $\begin{array}{l}\text { Age: } 23 \pm 3 \\
\text { Sex: } 25 \% \mathrm{~F}\end{array}$ & 54 & $\begin{array}{l}\text { Self-reported } \\
\text { (past } 6 \text { months) }\end{array}$ & $\begin{array}{c}\text { Summer } \\
108.9(102.8-115.4) \\
\text { Winter } \\
86.8(81.8-92.1) \\
\end{array}$ & NA & NA & $\begin{array}{l}\text { Crystal Chem } \\
\text { enzymatic assay }\end{array}$ \\
\hline \multicolumn{12}{|c|}{ Prospective Cohort Studies } \\
\hline $\begin{array}{l}\text { Aregbesola, A. } \\
\text { (2013) [25] }\end{array}$ & 1998-2011 & 10 years & Pneumonia & $\begin{array}{l}\text { KIHD study: middle age and } \\
\text { aging people }\end{array}$ & $\begin{array}{l}\text { Age: } 53-73 \\
\text { Sex: } 49 \% \mathrm{~F}\end{array}$ & 1421 & Clinically diagnosed & $43.5(17.8)$ & $\begin{array}{l}\text { tertile 1: } \\
8.9-33.8\end{array}$ & $\begin{array}{l}\text { tertile 3: } \\
50.8-112.8\end{array}$ & HPLC \\
\hline $\begin{array}{l}\text { Porojnicu, A. C. } \\
\text { (2012) [36] }\end{array}$ & 2007 & $\begin{array}{l}\text { winter } \\
\text { season }\end{array}$ & ARTI & $\begin{array}{l}\text { Medical employees from a } \\
\text { hospital }\end{array}$ & $\begin{array}{l}\text { Age: } 20-57 \\
\text { Sex: } 94 \% \mathrm{~F}\end{array}$ & 105 & $\begin{array}{l}\text { Laboratory or x-ray } \\
\text { confirmed }\end{array}$ & & NA & NA & HPLC \\
\hline $\begin{array}{l}\text { Sabetta, J.R. (2010) } \\
\text { [26] }\end{array}$ & 2009-2010 & 5 months & Viral ARTI & Healthy adults & $\begin{array}{l}\text { Age: } 20-88 \\
\text { Sex: } 57 \% \mathrm{~F}\end{array}$ & 198 & $\begin{array}{l}\text { Clinically diagnosed } \\
\text { Laboratory confirmed }\end{array}$ & $71.0(2.0)$ & 95 & $\geq 95$ & Diasorin CLIA \\
\hline He, C-S. (2013) [15] & 2011 & 4 months & URTI & Young athletes & $\begin{array}{l}\text { Age: } 18-40 \\
\text { Sex: } 30 \% \mathrm{~F}\end{array}$ & 225 & $\begin{array}{c}\text { Self-reported } \\
\text { (4 month diaries) }\end{array}$ & $53.0(40.0-66.0)$ & $12-30$ & $>120$ & HPLC \\
\hline
\end{tabular}

Abbreviations: ARTI = acute respiratory tract infection; $\mathrm{CAP}=$ community acquired pneumonia; CBP = competitive protein binding; KIHD = Kuopio Ischemic Heart Disease Risk Factor; IDS=Immunodiagnostic Systems; RIA=radioimmunoassay; CLIA=chemiluminescence immunoassay; HPLC = high performance liquid chromatography; LRTI = lower respiratory tract infection; MS = mass spectrometry; NA = not available; NEO = Netherlands Epidemiology of Obesity study; NHANES = National Health and Nutrition Examination Survey; URTI = upper respiratory tract infection. 
Table 2. Characteristics of studies reporting the association between severity of ARTI and 25(OH)D.

\begin{tabular}{|c|c|c|c|c|c|c|c|c|c|c|c|}
\hline $\begin{array}{c}\text { First Author } \\
\text { (Publication Year) }\end{array}$ & $\begin{array}{l}\text { Year of } \\
\text { Study }\end{array}$ & $\begin{array}{l}\text { Follow-Up } \\
\text { Time }\end{array}$ & Outcome & Participants & $\begin{array}{l}\text { Age }(\text { Mean } \\
\pm \text { SD)/Sex } \\
(\% \text { Female) }\end{array}$ & $\begin{array}{l}\text { Sample } \\
\text { Size }\end{array}$ & Severity Measurement & $\begin{array}{c}\text { Mean (SD)/Median } \\
\text { (IQR) 25(OH)D (nmol/L) }\end{array}$ & $\begin{array}{l}\text { Lowest } \\
\text { 25(OH)D } \\
\text { Category } \\
\text { (nmol/L) } \\
\end{array}$ & $\begin{array}{l}\text { Highest } \\
25(\mathrm{OH}) \mathrm{D} \\
\text { Category } \\
(\mathrm{nmol} / \mathrm{L})\end{array}$ & $\begin{array}{l}\text { 25(OH)D } \\
\text { Measure ment } \\
\text { Method }\end{array}$ \\
\hline \multicolumn{12}{|c|}{ Cross-Sectional Studies } \\
\hline $\begin{array}{c}\text { Mamani, M. (2017) } \\
\text { [45] }\end{array}$ & NA & & $\begin{array}{l}\text { Pneumonia } \\
\text { severity }\end{array}$ & $\begin{array}{l}\text { Hospitalised patients } \\
\text { with CAP }\end{array}$ & $\begin{array}{l}\text { Age: } 68 \pm 10 \\
\text { Sex: } 29 \% \mathrm{~F}\end{array}$ & 73 & $\begin{array}{c}\text { CURB-65 > } 2 \\
\text { ICU admission } \\
\text { Death }\end{array}$ & $\begin{array}{c}\text { Severe: } 52.8(77.5) \\
\text { Non-severe: } 56.5(48.0) \\
\text { Yes: } 59.8(88.4) \\
\text { No: } 52.8(47.6) \\
\text { Yes: } 64.6(91.8) \\
\text { No: } 53.0(55.4)\end{array}$ & $<25$ & $\geq 75$ & Diasorin CLIA \\
\hline $\begin{array}{l}\text { Pletz, M. W. (2014) } \\
\text { [14] }\end{array}$ & 2002-2008 & & $\begin{array}{l}\text { Pneumonia } \\
\text { severity }\end{array}$ & $\begin{array}{l}\text { Participants with } \\
\text { pneumonia }\end{array}$ & $\begin{array}{l}\text { Age: } \geq 18 \\
\text { Sex: } 43 \% \mathrm{~F}\end{array}$ & 300 & Hospitalisation & $\begin{array}{c}\text { Severe: } 32.0(19.5) \\
\text { Non-severe: } 40.5(25.0)\end{array}$ & NA & NA & Diasorin CLIA \\
\hline $\begin{array}{l}\text { Robertsen, S. } \\
\text { (2014) [46] }\end{array}$ & 2007-2008 & & ARTI & $\begin{array}{l}\text { Troms } \varnothing \\
\text { population-based study }\end{array}$ & $\begin{array}{l}\text { Age: } \geq 40 \\
\text { Sex: } \% \mathrm{~F}\end{array}$ & 791 & Duration of the illness & & NA & NA & Roche CLIA \\
\hline Lu, D. (2017) [13] & 2011 & & $\begin{array}{l}\text { Pneumonia } \\
\text { severity }\end{array}$ & $\begin{array}{l}\text { Patients with } \\
\text { pneumonia }\end{array}$ & $\begin{array}{l}\text { Age: } 60-94 \\
\text { Sex: } 31 \% \mathrm{~F}\end{array}$ & 49 & Duration of hospitalisation & & $<25$ & $\geq 25$ & IDS ELISA \\
\hline$\underset{\text { Kim, H.J. (2015) }}{\text { [41] }}$ & 2012-2014 & & $\begin{array}{l}\text { Pneumonia } \\
\text { severity }\end{array}$ & $\begin{array}{l}\text { Hospitalised patients } \\
\text { with CAP }\end{array}$ & $\begin{array}{l}\text { Age: } 18-96 \\
\text { Sex: } 34 \% \mathrm{~F}\end{array}$ & 797 & $\begin{array}{l}\text { 28-day all-cause mortality } \\
\text { Need for mechanical } \\
\text { ventilator }\end{array}$ & & $<50$ & $\geq 50$ & CLIA \\
\hline $\begin{array}{c}\text { Brance, M. (2018) } \\
\text { [39] }\end{array}$ & 2015-2016 & & $\begin{array}{l}\text { Pneumonia } \\
\text { severity }\end{array}$ & $\begin{array}{l}\text { Hospitalised patients } \\
\text { with CAP }\end{array}$ & $\begin{array}{l}\text { Age: }>18 \\
\text { Sex: } 59 \% \mathrm{~F}\end{array}$ & 167 & CURB-65 $\geq 2$ & $\begin{array}{c}\text { Severe: } 29.0(18.3) \\
\text { Non-severe: } 29.8(18.8)\end{array}$ & $<25$ & $>50$ & Siemens CLIA \\
\hline $\begin{array}{l}\text { Yaghoobi, M.H. } \\
\text { (2019) [44] }\end{array}$ & 2015 & & $\begin{array}{l}\text { Ventilator-asso } \\
\text { pneumonia }\end{array}$ & $\begin{array}{l}\text { Hospitalised patients } \\
\text { with } \\
\text { ventilator-associated } \\
\text { pneumonia }\end{array}$ & $\begin{array}{l}\text { Age: } 18-82 \\
\text { Sex: } 37 \% \mathrm{~F}\end{array}$ & 84 & $\begin{array}{l}\text { Mortality in } 28 \text { days } \\
\text { Blood culture } \\
\text { Duration of ventilation } \\
\text { SOFA score }\end{array}$ & $\begin{array}{c}\text { Yes: } 61.5(23.7) \\
\text { No: } 61.9(20.8) \\
\text { Positive: } 53.4(12.3) \\
\text { Negative: } 62.7(22.3)\end{array}$ & $<75$ & $\geq 75$ & NA \\
\hline $\begin{array}{c}\text { Scullion, L. (2018) } \\
\text { [47] }\end{array}$ & NA & & ARTI & $\begin{array}{l}\text { Elite rugby players and } \\
\text { rowers }\end{array}$ & $\begin{array}{l}\text { Age: } 23 \pm 3 \\
\text { Sex: } 25 \% \mathrm{~F}\end{array}$ & 53 & Duration of the illness & $\begin{array}{l}\text { Summer: } 4.8(3.0) \\
\text { Winter: } 6.9(4.3)\end{array}$ & NA & NA & $\begin{array}{l}\text { Crystal Chem } \\
\text { enzymatic assay }\end{array}$ \\
\hline \multicolumn{12}{|c|}{ Prospective Cohort Studies } \\
\hline $\begin{array}{l}\text { Laaksi, I. (2007) } \\
\quad[16]\end{array}$ & 2002 & 6 months & $\begin{array}{c}\text { ARTI } \\
\text { severity }\end{array}$ & Young military men & $\begin{array}{l}\text { Age: } \geq 18 \\
\text { Sex: } 0 \% \mathrm{~F}\end{array}$ & 652 & $\begin{array}{l}\text { Number of days absence from } \\
\text { duty due to ARTI }\end{array}$ & & $<40$ & $\geq 40$ & IDS OCTEIA \\
\hline $\begin{array}{l}\text { Remmelts, H.F. } \\
\quad(2012)[43]\end{array}$ & $2007-2010$ & 30 days & $\begin{array}{l}\text { Pneumonia } \\
\text { severity }\end{array}$ & $\begin{array}{l}\text { Hospitalised patients } \\
\text { with CAP }\end{array}$ & $\begin{array}{l}\text { Age: } \geq 18 \\
\text { Sex: } 44 \% \mathrm{~F}\end{array}$ & 272 & $\begin{array}{c}\text { 30-day mortality } \\
\text { PSI }>3\end{array}$ & $\begin{array}{l}\text { ICU: } 34.9(23.8-46.3) \\
\text { No ICU: } 48.3(30.8-68.4) \\
\text { Yes: } 25.8(19.8-40.1) \\
\text { No: } 48.8(32.4-68.9)\end{array}$ & $<50$ & $>75$ & Diasorin CLIA \\
\hline $\begin{array}{l}\text { Holter, J.C. (2016) } \\
\text { [40] }\end{array}$ & 2008-2014 & 6 years & $\begin{array}{l}\text { Pneumonia } \\
\text { severity }\end{array}$ & $\begin{array}{l}\text { Hospitalised patients } \\
\text { with CAP }\end{array}$ & $\begin{array}{l}\text { Age: } \geq 18 \\
\text { Sex: } 49 \% \mathrm{~F}\end{array}$ & 241 & $\begin{array}{c}\text { CURB- } 65 \geq 3 \\
\text { ICU admission } \\
\text { Long-term all-cause mortality }\end{array}$ & & $<30$ & $\geq 50$ & Siemens CLIA \\
\hline $\begin{array}{c}\text { Leow, L. (2011) } \\
\text { [42] }\end{array}$ & 2008 & 4 months & $\begin{array}{l}\text { Pneumonia } \\
\text { severity }\end{array}$ & $\begin{array}{l}\text { Hospitalised patients } \\
\text { with CAP }\end{array}$ & $\begin{array}{l}\text { Age: } 16-97 \\
\text { Sex: NA }\end{array}$ & 112 & 30-day mortality & & $<30$ & $>50$ & Roche CLIA \\
\hline $\begin{array}{c}\text { Sabetta, J.R. (2010) } \\
\text { [26] }\end{array}$ & 2009-2010 & 5 months & $\begin{array}{l}\text { Viral ARTI } \\
\text { severity }\end{array}$ & Healthy adults & $\begin{array}{l}\text { Age: } 20-88 \\
\text { Sex: } 57 \% \mathrm{~F}\end{array}$ & 198 & Duration of the illness & & $<95$ & $\geq 95$ & Diasorin CLIA \\
\hline He, C-S. (2013) [15] & 2011 & 4 months & $\begin{array}{c}\text { URTI } \\
\text { severity }\end{array}$ & Young athletes & $\begin{array}{l}\text { Age: } 18-40 \\
\text { Sex: } 31 \% \mathrm{~F}\end{array}$ & 103 & $\begin{array}{l}\text { Duration of the illness } \\
\text { SSC }\end{array}$ & & $12-30$ & $>120$ & HPLC \\
\hline
\end{tabular}

Abbreviations: ARTI = acute respiratory tract infection; $\mathrm{CAP}=$ community acquired pneumonia; CURB- 65 = confusion, uremia, respiratory rate, low blood pressure, age $\geq 65$ years; ICU = intensive care unit; LC = liquid chromatography; LRTI = lower respiratory tract infection; MS = mass spectrometry; NA = not available; PSI = pulmonary severity score; SSC = symptom severity score; URTI = upper respiratory tract infection. 
ARTI risk was measured by (i) self-report via survey questionnaire or symptom diaries $(n=10)$, or (ii) clinical diagnosis with or without confirmation from X-ray or a laboratory test $(n=6)$. ARTI severity was measured using a severity index $(n=6)$ such as CURB or CURB-65 (confusion, uraemia, respiratory rate, low blood pressure, age $\geq 65$ ), pulmonary severity score (PSI), or symptom severity score (SSC); duration of the illness $(n=10)$; admission to hospital or intensive care units $(n=4)$; or mortality $(n=6)$. All 24 studies had a moderate-to-high quality score (Table S1).

\subsection{Association between 25(OH)D Concentration and Risk of ARTI}

We included 14 of the 16 studies that assessed the association between $25(\mathrm{OH}) \mathrm{D}$ concentration and risk of ARTI in the meta-analysis comparing the risk of ARTI in the lowest versus the highest $25(\mathrm{OH}) \mathrm{D}$ category ( $N$ participants $=78,127$ ) and 10 studies were included in the trend analysis $(N$ participants $=$ $69,048)$. Five studies reported risk of ARTI in at least three categories of $25(\mathrm{OH}) \mathrm{D}$ concentration and the number of cases by exposure category; these were included in the evaluation of whether there is a non-linear relationship between ARTI risk and 25(OH)D concentration ( $N$ participants $=37,902)$.

There was a significantly higher risk of ARTI in the lowest compared with the highest $25(\mathrm{OH}) \mathrm{D}$ category (pooled OR 1.83; 95\% CI 1.42-2.37; $\mathrm{I}^{2}=78.8 \% ; p<0.001$ ) (Figure 2). The pooled OR per $10 \mathrm{nmol} / \mathrm{L}$ decrease in 25(OH)D was $1.02\left(95 \% \mathrm{CI} 0.97-1.07 ; \mathrm{I}^{2}=72.7 \% ; p<0.001\right.$ ) (Figure 3). There was a significant non-linear relationship ( $p$ for non-linearity $=0.029$ ) with inflexion points at $60 \mathrm{nmol} / \mathrm{L}$ and $37.5 \mathrm{nmol} / \mathrm{L}$. The steepest increased risk occurred below $37.5 \mathrm{nmol} / \mathrm{L}$ (Figure 4). Although both linear and spline models were significant, the spline model fitted the data better.

\begin{tabular}{|c|c|c|c|c|}
\hline \multirow{3}{*}{$\begin{array}{l}\begin{array}{l}\text { Author } \\
\text { (year) }\end{array} \\
\text { Rafiq, R. (2018) }\end{array}$} & \multirow{2}{*}{\multicolumn{2}{|c|}{$\begin{array}{l}\text { Participants } \\
\text { (n) }\end{array}$}} & \multirow{3}{*}{$\begin{array}{l}\text { OR }(95 \% \mathrm{Cl}) \\
1.46(1.25,1.71)\end{array}$} & \multirow{3}{*}{$\begin{array}{l}\% \\
\text { Weight } \\
11.07\end{array}$} \\
\hline & & & & \\
\hline & 6138 & \multirow{2}{*}{+} & & \\
\hline Mamani, M. (2017) & 149 & & $3.69(1.46,9.31)$ & 4.56 \\
\hline Lu, D. (2017) & 163 & \multirow[t]{2}{*}{$\vdots$} & $10.22(4.36,23.98)$ & 5.03 \\
\hline Nanri, A. (2017) & 532 & & $1.30(0.63,2.69)$ & 5.95 \\
\hline Monlezun, D. J. (2015) & 14108 & & $2.75(1.67,4.54)$ & 7.99 \\
\hline Khalid, A. N. (2015) & 3921 & & $1.33(1.03,1.72)$ & 10.34 \\
\hline Robertsen, S. (2014) & 6350 & & $0.87(0.70,1.09)$ & 10.62 \\
\hline Jovanovich, A. J. (2014) & 132 & & $0.96(0.35,2.61)$ & 4.12 \\
\hline Quraishi, S. A. (2013) & 16975 & + & $2.25(1.26,4.01)$ & 7.23 \\
\hline He, C. S. (2013) & 225 & & $5.41(1.04,28.28)$ & 1.97 \\
\hline Aregbesola, A. (2013) & 1421 & & $2.40(1.20,4.90)$ & 6.13 \\
\hline Berry, D. J. (2011) & 6789 & $\rightarrow$ & $2.00(1.22,3.27)$ & 8.06 \\
\hline Sabetta, J. R. (2010) & 198 & $\rightarrow$ & $1.96(1.07,3.59)$ & 6.98 \\
\hline Ginde, A. A. (2009) & 18883 & +1 & $1.36(1.01,1.84)$ & 9.95 \\
\hline \multicolumn{2}{|c|}{ Overall $(I-$ squared $=78.8 \%, p=0.000)$} & ४े & $1.83(1.42,2.37)$ & 100.00 \\
\hline NOTE: Weights are from & random effects analysis & & & \\
\hline
\end{tabular}

Figure 2. Forest plot displaying odds ratios (OR) and $95 \%$ confidence intervals $(95 \% \mathrm{CI})$ for the association between $25(\mathrm{OH}) \mathrm{D}$ concentration and acute respiratory tract infection, comparing the lowest versus the highest $25(\mathrm{OH}) \mathrm{D}$ category. 


\begin{tabular}{|c|c|c|c|}
\hline \multirow{2}{*}{$\begin{array}{l}\text { Author } \\
\text { (year) }\end{array}$} & Participants & \multicolumn{2}{|r|}{$\%$} \\
\hline & (n) & $\mathrm{OR}(95 \% \mathrm{Cl})$ & Weight \\
\hline Rafiq, R. (2018) & 6138 & $1.00(0.95,1.04)$ & 15.22 \\
\hline Mamani, M. (2017) & 149 & $1.27(1.02,1.58)$ & 3.48 \\
\hline Nanri, A. (2017) & 532 & $0.95(0.86,1.05)$ & 9.62 \\
\hline Monlezun, D. J. (2015) & 14108 & $1.00(0.95,1.06)$ & 14.22 \\
\hline Khalid, A. N. (2015) & 3921 & $1.05(1.00,1.10)$ & 14.98 \\
\hline Jovanovich, A. J. (2014) & 132 & $1.06(0.68,1.69)$ & 0.95 \\
\hline Quraishi, S. A. (2013) & 16975 & $0.93(0.89,0.98)$ & 14.92 \\
\hline Aregbesola, A. (2013) & 1421 & $1.12(0.78,1.61)$ & 1.45 \\
\hline Berry, D. J. (2011) & 6789 & $1.09(1.05,1.14)$ & 15.63 \\
\hline Ginde, A. A. (2009) & 18883 & $1.04(0.94,1.15)$ & 9.53 \\
\hline \multicolumn{2}{|c|}{ Overall (I-squared $=72.7 \%, p=0.000$ ) } & $1.02(0.97,1.07)$ & 100.00 \\
\hline \multicolumn{2}{|c|}{ NOTE: Weights are from random effects analysis } & & \\
\hline
\end{tabular}

Figure 3. Forest plot displaying odds ratios (OR) and $95 \%$ confidence intervals (95\% CI) of acute respiratory tract infection risk per $10 \mathrm{nmol} / \mathrm{L}$ decrease in $25(\mathrm{OH}) \mathrm{D}$ concentration.

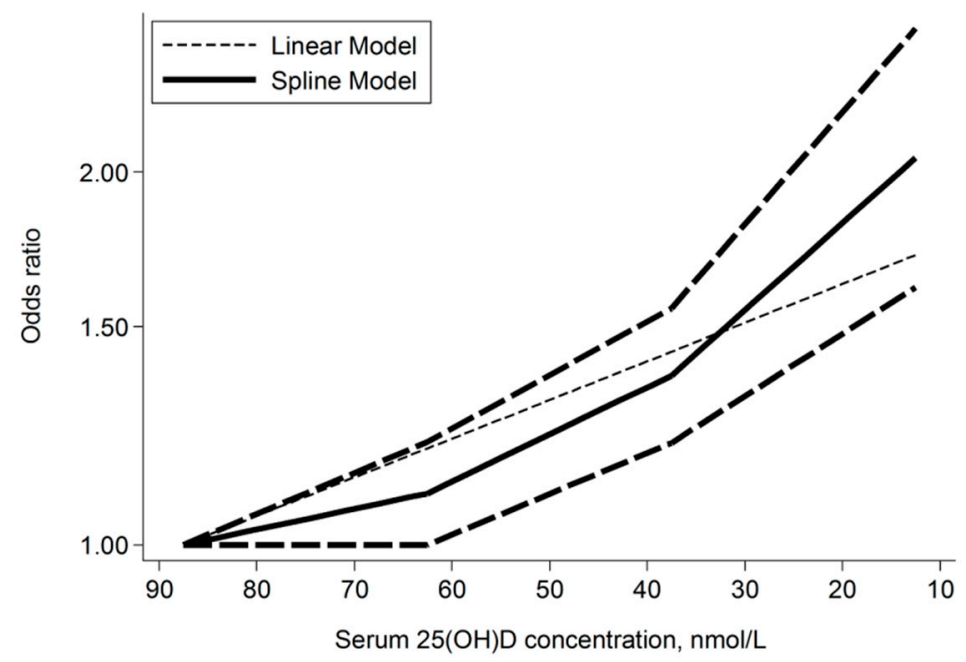

Figure 4. Dose-response relationship between serum $25(\mathrm{OH}) \mathrm{D}$ concentration and odds ratio of acute respiratory tract infection ( $p$ for non-linearity $=0.029$ ). Lines with long dashes represent the upper and lower confidence interval for the fitted non-linear trend (solid line).

\subsection{Association between $25(\mathrm{OH})$ D Concentration and Severity of ARTI}

Five studies ( $N$ participants $=1495)$ were included in the meta-analysis of the odds of severe ARTI or mortality combined, comparing the highest and the lowest $25(\mathrm{OH}) \mathrm{D}$ category and four studies $(N$ participants $=1422)$ were included in the mortality meta-analysis. The pooled ORs for severity/mortality combined and mortality separately were 2.46 (95\% CI 1.65-3.66; $\mathrm{I}^{2}=49.8 \% ; p=0.093$ ) and $3.00\left(95 \%\right.$ CI $\left.1.89-4.78 ; \mathrm{I}^{2}=66.7 \% ; p=0.029\right)$, respectively (Figure 5). The duration of ARTI was also inversely associated with $25(\mathrm{OH}) \mathrm{D}$ concentration; low $25(\mathrm{OH}) \mathrm{D}$ concentration was associated with a more prolonged ARTI in 7 out of 10 studies (Table 3 ). 


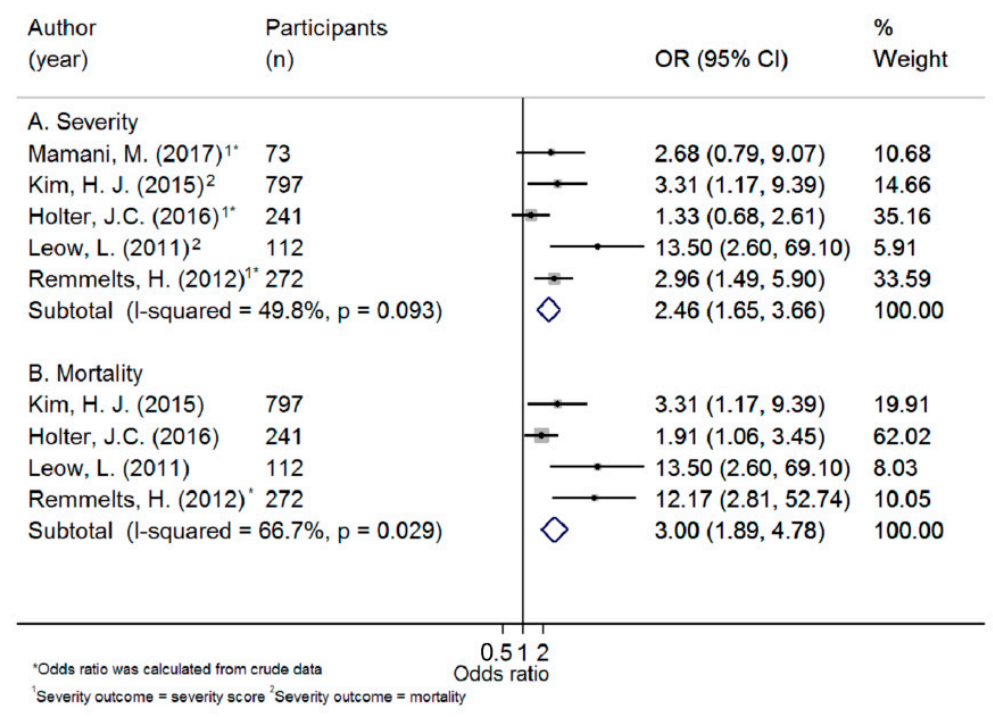

Figure 5. Forest plot displaying odds ratios (OR) and 95\% confidence interval (95\% CI) for the association between $25(\mathrm{OH}) \mathrm{D}$ concentration and $(\mathrm{A})$ severe acute respiratory tract infection, and (B) mortality, comparing the lowest versus the highest $25(\mathrm{OH}) \mathrm{D}$ category.

Table 3. Studies reporting duration of illness according to $25(\mathrm{OH}) \mathrm{D}$ concentration.

\begin{tabular}{|c|c|c|c|}
\hline \multirow{2}{*}{ First Author (Published Year) } & \multicolumn{2}{|c|}{ Duration of Illness Mean (SD)/Median (IQR) (Days) } & \multirow{2}{*}{$p$-Value } \\
\hline & Lowest 25(OH)D Category & Highest 25(OH)D Category & \\
\hline Mamani, M. (2017) ${ }^{1}$ & $11.03(7.5)$ & $9.47(6.1)$ & \\
\hline Lu, D. $(2017)^{1}$ & $26.2(15.6)$ & $15.5(11.1)$ & 0.014 \\
\hline He, C-S. (2013) ${ }^{2}$ & $13(10-17)$ & $5(5-7)$ & $\leq 0.05$ \\
\hline Sabetta, J.R. (2010) ${ }^{2}$ & $6(2-8)$ & $6(2-27)$ & \\
\hline Laaksi, I. $(2007)^{3}$ & $4(2-6)$ & $2(0-4)$ & 0.004 \\
\hline Kim, H.J. (2015) ${ }^{1}$ & $12.5(15.4)$ & $10.3(11.0)$ & 0.570 \\
\hline Robertsen, S. (2014) ${ }^{2}$ & 14 & 13 & \\
\hline Yaghoobi, M.H. (2019) ${ }^{4}$ & $13.4(6.1)$ & $13.7(9.8)$ & 0.880 \\
\hline Holter, J.C. (2016) ${ }^{2}$ & $4(2-6)$ & $5(3-10)$ & \\
\hline Scullion, L. (2018) 2,a & $6.9(4.3)$ & $4.8(3.0)$ & 0.044 \\
\hline
\end{tabular}

Abbreviations: IQR = interquartile range; $\mathrm{SD}=$ standard deviation. ${ }^{1}$ Duration of hospitalisation; ${ }^{2}$ Duration of symptoms; ${ }^{3}$ Number of days of absence from duty due to acute respiratory tract infection; ${ }^{4}$ Duration of mechanical ventilation. ${ }^{a}$ The study reported duration of the symptoms, comparing winter and summer; the mean $25(\mathrm{OH}) \mathrm{D}$ for winter was $86.8 \mathrm{nmol} / \mathrm{L}$ and for summer was $108.9 \mathrm{nmol} / \mathrm{L}$.

\subsection{Studies Excluded from the Meta-Analysis}

Two studies were excluded from the meta-analysis of ARTI risk, and nine studies were excluded from the meta-analysis of ARTI severity. Reasons for exclusion and the main findings of the excluded studies are provided in Table S2. Studies that reported mean (SD) or median (interquartile range (IQR)) of 25(OH)D concentration in people with severe versus non-severe ARTI or mean (SD) severity score by $25(\mathrm{OH}) \mathrm{D}$ category were excluded. As different scales were used to measure ARTI severity across studies, we could not pool the mean difference in severity score between the highest and the lowest $25(\mathrm{OH}) \mathrm{D}$ category. Overall, results from 6/9 excluded studies showed an inverse association between $25(\mathrm{OH}) \mathrm{D}$ concentration and severity of ARTI measured by duration of the illness, severity score, or the number of days absent from duty (Table S2). 


\subsection{Subgroup Analysis and Publication Bias}

We found evidence of significant heterogeneity $\left(\mathrm{I}^{2}=78.8 \%, p<0.001\right)$; therefore, we conducted stratified meta-analyses to explore potential sources of heterogeneity (Figure 6A-D). The association between 25(OH)D concentration and LRTI was stronger than for URTI, but the former had significant heterogeneity (Figure 6A). Similarly, the association was stronger for studies with mean $25(\mathrm{OH}) \mathrm{D}$ concentration $<60 \mathrm{nmol} / \mathrm{L}$ than in those with mean 25(OH)D concentration $\geq 60 \mathrm{nmol} / \mathrm{L}$, but again with significant heterogeneity (Figure $6 \mathrm{C}$ ). There was only a small difference in the pooled OR between studies that used a fully adjusted model and those that reported estimates from crude models or those with less complete adjustment, but the latter had significant heterogeneity $\left(\mathrm{I}^{2}=87.2 \%, p<0.001\right)$ (Figure 6D).

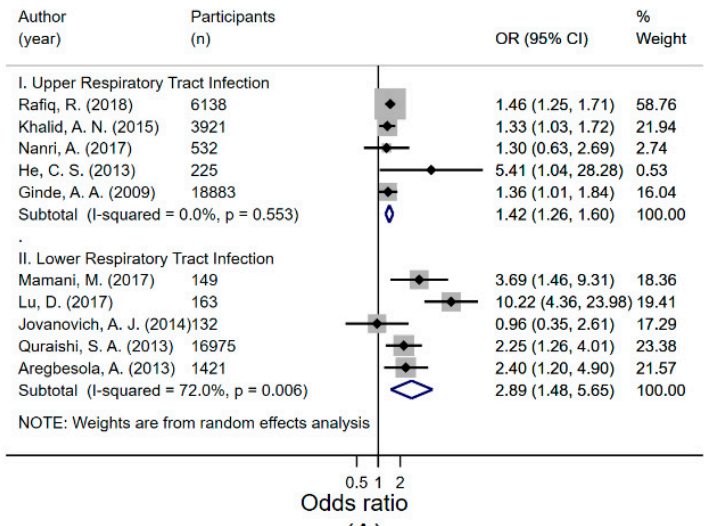

(A)

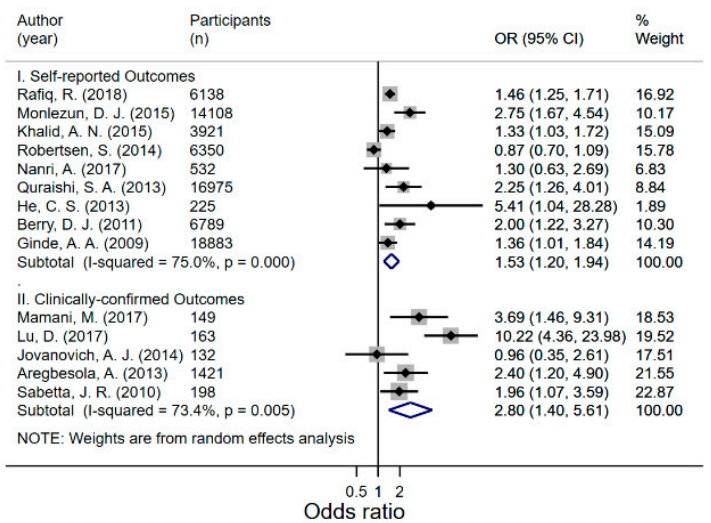

(B)

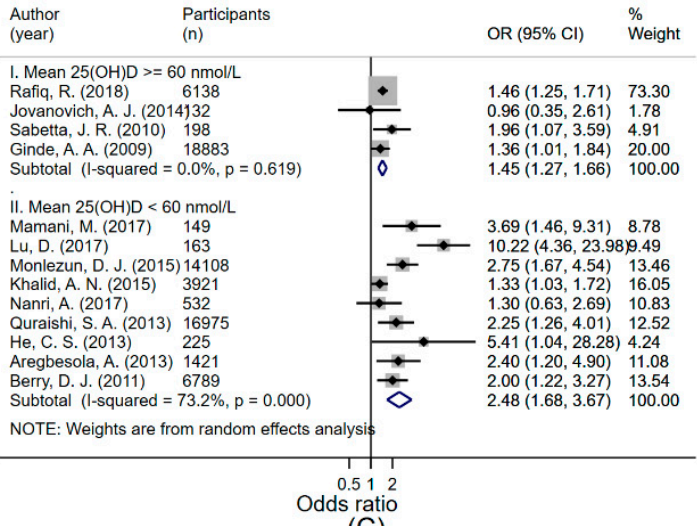

(C)

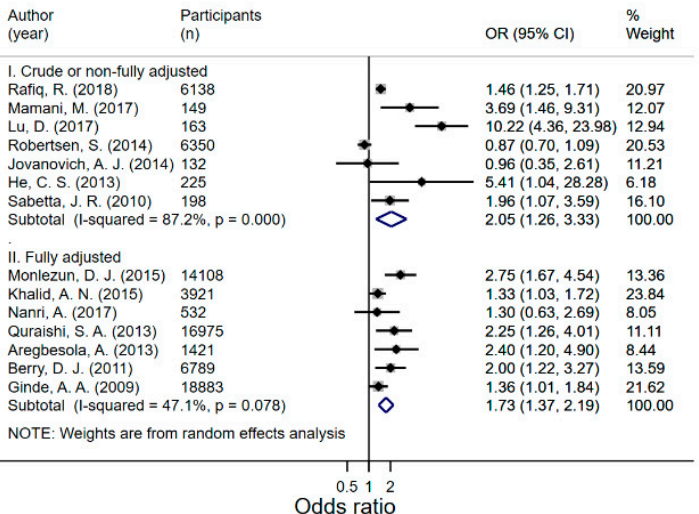

(D)

Figure 6. Forest plot displaying odds ratios (95\% confidence intervals) for the association between $25(\mathrm{OH}) \mathrm{D}$ concentration and (A) (i) upper respiratory tract infection, and (ii) lower respiratory tract infection; (B) (i) self-reported, and (ii) clinically confirmed acute respiratory tract infection; (C) acute respiratory tract infection in studies with (i) mean $25(\mathrm{OH}) \mathrm{D}$ concentration $\geq 60 \mathrm{nmol} / \mathrm{L}$, and (ii) mean $25(\mathrm{OH}) \mathrm{D}$ concentration $<60 \mathrm{nmol} / \mathrm{L}$; and (D) acute respiratory tract infection in studies with (i) crude or non-fully adjusted effect estimate; and (ii) fully adjusted effect estimate; comparing the lowest versus the highest $25(\mathrm{OH}) \mathrm{D}$ category.

The funnel plot shows evidence of significant publication bias $(p=0.024)$ (Figure 7), suggesting that studies with small sample size and insignificant findings were not published. 


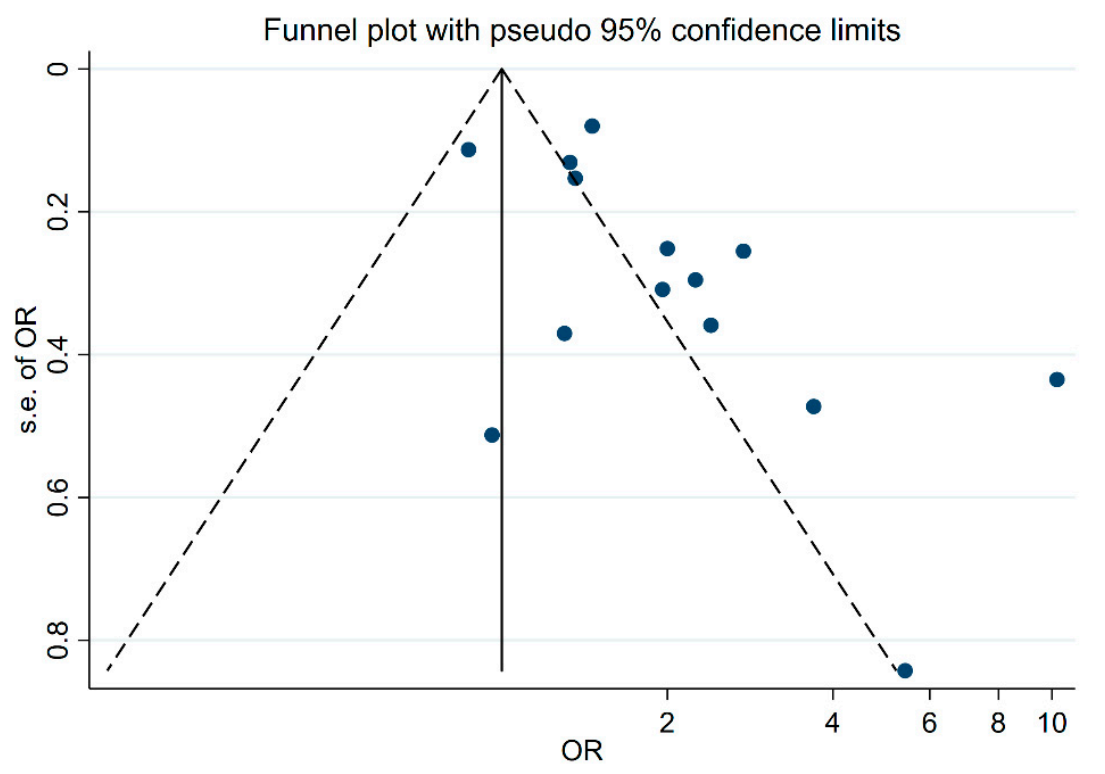

Figure 7. The funnel plot to check for publication bias.

\section{Discussion}

In this systematic review and meta-analysis, we observed significant associations between $25(\mathrm{OH}) \mathrm{D}$ concentration and both risk and severity of ARTI, but with significant heterogeneity and evidence of publication bias. There was a non-linear association between $25(\mathrm{OH}) \mathrm{D}$ concentration and risk of ARTI, with evidence of a more marked increased risk for $25(\mathrm{OH}) \mathrm{D}$ concentration below $37.5 \mathrm{nmol} / \mathrm{L}$.

Findings from our meta-analysis of ARTI risk, which includes the largest number of participants, are consistent with results from previous reports. A meta-analysis published in 2015 as an abstract $(n=44,301)$ reported an increased risk of ARTI in those with $25(\mathrm{OH}) \mathrm{D}<50 \mathrm{nmol} / \mathrm{l}$ compared with those $\geq 50 \mathrm{nmol} / \mathrm{L}$. The odds ratio was higher than we found ( $2.63 \mathrm{vs.} 1.83$ ); their analysis included children as well as adults and they did not present an estimate for adults and adolescents only [11]. A systematic review including 25 observational studies (10 in adults) reported significant inverse association between $25(\mathrm{OH}) \mathrm{D}$ concentration and risk of ARTI, but no formal meta-analysis was conducted [12]. The link between 25(OH)D concentration and risk of ARTI was also reported separately for children and LRTI; a meta-analysis showed a higher prevalence of vitamin D deficiency $(<50 \mathrm{nmol} / \mathrm{L})$ in children with LRTI $(n=550)[9]$.

This is the first study to our knowledge which performed a meta-analysis of the association between $25(\mathrm{OH}) \mathrm{D}$ concentration and severity of ARTI. We found a stronger association between $25(\mathrm{OH}) \mathrm{D}$ concentration and severity of ARTI than with risk of ARTI (OR 2.46 vs. 1.83). The result accords with findings from a systematic review that highlighted the potential link between vitamin D deficiency and severe LRTI in children, but no meta-analysis was included [9]. It is difficult to meta-analyse the association between $25(\mathrm{OH}) \mathrm{D}$ concentration and severity of ARTI because of variability across studies with respect to variability in assay methods used to measure serum $25(\mathrm{OH}) \mathrm{D}$; the cut points used to categorise $25(\mathrm{OH}) \mathrm{D}$ concentration; the scales used to measure severity; and the measures used to estimate effect. We could only include five studies in the severity meta-analysis so were unable to assess the association within subgroups or investigate a potential non-linear trend.

Results from RCTs are inconsistent. Some trials found that vitamin D supplementation reduced the risk of ARTI [48-50] while others did not [51-54]. The inconsistency may be due to differences in study design, vitamin $\mathrm{D}$ supplement doses and regimens, and different baseline $25(\mathrm{OH}) \mathrm{D}$ concentration. The most recent meta-analysis, using individual participant data, found that vitamin D supplementation reduced the risk of ARTI more strongly in people with $25(\mathrm{OH}) \mathrm{D}$ concentration $<25 \mathrm{nmol} / \mathrm{L}$ [22]. Our findings suggest that supplementation may be of most benefit in people with a $25(\mathrm{OH}) \mathrm{D}$ 
concentration $\leq 37.5 \mathrm{nmol} / \mathrm{L}$, with some benefit up to $60 \mathrm{nmol} / \mathrm{L}$, although these values should be considered with caution in light of the different assays and markedly varying cut point used across studies.

We observed high heterogeneity, and this mostly persisted in subgroup analyses. Despite this, the direction of effect was consistent; lower $25(\mathrm{OH}) \mathrm{D}$ concentration was associated with increased risk or severity of ARTI. There are indications of publication bias, indicating that small studies that showed no significant association were either not identified or not published. Publication bias has also been observed in meta-analyses of RCTs [17,22]. It is thus possible that the benefits of vitamin D for reducing risk or severity of ARTI have been over-estimated.

\section{Conclusions}

Our study is the largest to date and to the best of our knowledge, is the first to include a meta-analysis of the association between $25(\mathrm{OH}) \mathrm{D}$ concentration and severity of ARTI. Our findings suggest an important role of vitamin D in prevention of ARTI risk and severity, particularly in people with low $25(\mathrm{OH}) \mathrm{D}$ concentration. However, it is challenging to identify an optimal $25(\mathrm{OH}) \mathrm{D}$ concentration or a concentration below which supplementation would be of benefit due to the lack of consistency in both $25(\mathrm{OH}) \mathrm{D}$ assays and reporting across studies. It is important to improve consistency of reporting, as well as assays, to enable the field to move forward.

Supplementary Materials: The following are available online at http://www.mdpi.com/1660-4601/16/17/3020/s1, Table S1: Quality assessment based on the Newcastle-Ottawa Scale (NOS); Table S2: Studies excluded from the meta-analysis and main findings; File S1: Search strategies; File S2: The Newcastle-Ottawa Scale.

Author Contributions: Conceptualization, H.P. and R.N.; Methodology, H.P. and R.N.; Software, H.P. and A.M.; Validation, M.W. and R.N.; Formal Analysis, H.P., A.M., M.W., and R.N.; Investigations, H.P., A.R. and R.N.; Data Curation, H.P., A.R., and R.N.; Writing-Original Draft Preparation, H.P.; Writing—Review \& Editing, H.P., M.W., and R.N.; Supervision, R.N.

Funding: H.P. is supported by The University of Queensland PhD Scholarship, R.N. is funded by an NHMRC fellowship.

Conflicts of Interest: The authors declare no conflict of interest.

\section{References}

1. Heikkinen, T.; Jarvinen, A. The common cold. Lancet 2003, 361, 51-59. [CrossRef]

2. WHO. Review of global influenza activity, October 2016-October 2017. Wkly. Epidemiol. Rec. 2017, 92, 761-779.

3. LRICollaborators. Estimates of the global, regional, and national morbidity, mortality, and aetiologies of lower respiratory tract infections in 195 countries: A systematic analysis for the Global Burden of Disease Study 2015. Lancet Infect. Dis. 2017, 17, 1133-1161. [CrossRef]

4. Australian Government, Department of Health. Available online: http://www.health.gov.au/internet/main/ publishing.nsf/Content/ozflu-surveil-2017-final.htm\#current (accessed on 26 April 2019).

5. Telcian, A.G.; Zdrenghea, M.T.; Edwards, M.R.; Laza-Stanca, V.; Mallia, P.; Johnston, S.L.; Stanciu, L.A. Vitamin D increases the antiviral activity of bronchial epithelial cells in vitro. Antivir. Res. 2017, 137, 93-101. [CrossRef] [PubMed]

6. Zdrenghea, M.T.; Makrinioti, H.; Bagacean, C.; Bush, A.; Johnston, S.L.; Stanciu, L.A. Vitamin D modulation of innate immune responses to respiratory viral infections. Rev. Med. Virol. 2017, 27. [CrossRef]

7. Assa, A.; Vong, L.; Pinnell, L.J.; Avitzur, N.; Johnson-Henry, K.C.; Sherman, P.M. Vitamin D deficiency promotes epithelial barrier dysfunction and intestinal inflammation. J. Infect. Dis 2014, 210, 1296-1305. [CrossRef] [PubMed]

8. Bartley, J. Vitamin D, innate immunity and upper respiratory tract infection. J. Laryngol. Otol. 2010, 124, 465-469. [CrossRef]

9. Jat, K.R. Vitamin D deficiency and lower respiratory tract infections in children: A systematic review and meta-analysis of observational studies. Trop. Doct. 2017, 47, 77-84. [CrossRef] [PubMed] 
10. García-Marcos, L.; Morales, E.; Pacheco-Gonzalez, R.M. Prenatal vitamin D status and respiratory and allergic outcomes in childhood: A meta-analysis of observational studies. Pediatr. Allergy Immunol. 2018, 29, 243-253.

11. Furlong, K.; Omand, J.; Pitino, M.; Science, M.; O'Connor, D.; Maguire, J.; Tran, D. Vitamin D Status and Respiratory Tract Infections: A Systematic Review and Meta-Analysis of Observational Evidence. FASEB J. 2015, 29, 252-255.

12. Jolliffe, D.A.; Griffiths, C.J.; Martineau, A.R. Vitamin D in the prevention of acute respiratory infection: Systematic review of clinical studies. J. Steroid Biochem. Mol. Boil. 2013, 136, 321-329. [CrossRef] [PubMed]

13. Lu, D.; Zhang, J.; Ma, C.; Yue, Y.; Zou, Z.; Yu, C.; Yin, F. Link between community-acquired pneumonia and vitamin D levels in older patients. Z. Gerontol. Geriatr. 2017, 51, 435-439. [CrossRef] [PubMed]

14. Pletz, M.W.; Terkamp, C.; Schumacher, U.; Rohde, G.; Schütte, H.; Welte, T.; Bals, R. Vitamin D deficiency in community-acquired pneumonia: Low levels of $1,25(\mathrm{OH})_{2} \mathrm{D}$ are associated with disease severity. Respir. Res. 2014, 15, 53. [CrossRef] [PubMed]

15. He, C.-S.; Handzlik, M.; Fraser, W.D.; Muhamad, A.; Preston, H.; Richardson, A.; Gleeson, M. Influence of vitamin $\mathrm{D}$ status on respiratory infection incidence and immune function during 4 months of winter training in endurance sport athletes. Exerc. Immunol. Rev. 2013, 19, 86-101. [PubMed]

16. Laaksi, I.; Ruohola, J.-P.; Tuohimaa, P.; Auvinen, A.; Haataja, R.; Pihlajamäki, H.; Ylikomi, T. An association of serum vitamin D concentrations $<40 \mathrm{nmol} / \mathrm{L}$ with acute respiratory tract infection in young Finnish men. Am. J. Clin. Nutr. 2007, 86, 714-717. [PubMed]

17. Bergman, P.; Lindh, A.U.; Björkhem-Bergman, L.; Lindh, J.D. Vitamin D and Respiratory Tract Infections: A Systematic Review and Meta-Analysis of Randomized Controlled Trials. PLoS ONE 2013, 8, e65835. [CrossRef] [PubMed]

18. Charan, J.; Goyal, J.P.; Saxena, D.; Yadav, P. Vitamin D for prevention of respiratory tract infections: A systematic review and meta-analysis. J. Pharmacol. Pharm. 2012, 3, 300-303. [CrossRef] [PubMed]

19. Mao, S.; Huang, S. Vitamin D supplementation and risk of respiratory tract infections: A meta-analysis of randomized controlled trials. Scand. J. Infect. Dis. 2013, 45, 696-702. [CrossRef] [PubMed]

20. Gysin, D.V.; Dao, D.; Lytvyn, L.; Loeb, M. Effect of Vitamin D3 Supplementation on Respiratory Tract Infections in Healthy Individuals: A Systematic Review and Meta-Analysis of Randomized Controlled Trials. PLOS ONE 2016, 11, 0162996.

21. Xiao, L.; Xing, C.; Yang, Z.; Xu, S.; Wang, M.; Du, H.; Liu, K.; Huang, Z. Vitamin D supplementation for the prevention of childhood acute respiratory infections: A systematic review of randomised controlled trials. Br. J. Nutr. 2015, 114, 1026-1034. [CrossRef]

22. Martineau, A.R.; Jolliffe, D.A.; Hooper, R.L.; Greenberg, L.; Aloia, J.F.; Bergman, P.; Dubnov-Raz, G.; Esposito, S.; Ganmaa, D.; Ginde, A.A.; et al. Vitamin D supplementation to prevent acute respiratory tract infections: Systematic review and meta-analysis of individual participant data. BMJ 2017, 356, i6583. [CrossRef]

23. PROSPERO. Available online: https://www.crd.york.ac.uk/prospero/display_record.php?RecordID=94987/ (accessed on 1 May 2019).

24. Wells, G.; Shea, B.J.; O'Connell, D.; Peterson, J.; Welch, V.; Losos, M.; Tugwell, P. The Newcastle-Ottawa Scale (NOS) for Assessing the Quality of Non-Randomized Studies in Meta-Analysis. Available online: http://www.ohri.ca/programs/clinical_epidemiology/oxford.asp (accessed on 16 July 2019).

25. Aregbesola, A.; Voutilainen, S.; Nurmi, T.; Virtanen, J.; Ronkainen, K.; Tuomainen, T.-P. Serum 25-hydroxyvitamin D3 and the risk of pneumonia in an ageing general population. J. Epidemiol. Commun. Heal. 2013, 67, 533-536. [CrossRef] [PubMed]

26. Sabetta, J.R.; DePetrillo, P.; Cipriani, R.J.; Smardin, J.; Burns, L.A.; Landry, M.L. Serum 25-Hydroxyvitamin D and the Incidence of Acute Viral Respiratory Tract Infections in Healthy Adults. PLoS ONE 2010, 5, e11088. [CrossRef] [PubMed]

27. Greenland, S.; Longnecker, M.P. Methods for Trend Estimation from Summarized Dose-Response Data, with Applications to Meta-Analysis. Am. J. Epidemiol. 1992, 135, 1301-1309. [CrossRef]

28. Orsini, N.; Bellocco, R.; Greenland, S. Generalized Least Squares for Trend Estimation of Summarized Dose-response Data. Stata J. Promot. Commun. Stat. Stata 2006, 6, 40-57. [CrossRef] 
29. Ginde, A.A.; Mansbach, J.M.; Camargo, C.A. Association between serum 25-hydroxyvitamin D level and upper respiratory tract infection in the Third National Health and Nutrition Examination Survey. Arch. Intern. Med. 2009, 169, 384-390. [CrossRef]

30. Touvier, M.; Chan, D.S.; Lau, R.; Aune, D.; Vieira, R.; Greenwood, D.C.; Kampman, E.; Riboli, E.; Hercberg, S.; Norat, T. Meta-Analyses of Vitamin D Intake, 25-Hydroxyvitamin D Status, Vitamin D Receptor Polymorphisms, and Colorectal Cancer Risk. Cancer Epidemiol. Biomark. Prev. 2011, 20, 1003-1016. [CrossRef] [PubMed]

31. Berry, D.J.; Hesketh, K.; Power, C.; Hyppönen, E. Vitamin D status has a linear association with seasonal infections and lung function in British adults. Br. J. Nutr. 2011, 106, 1433-1440. [CrossRef] [PubMed]

32. Jovanovich, A.J.; Ginde, A.A.; Holmen, J.; Jablonski, K.; Allyn, R.L.; Kendrick, J.; Chonchol, M. Vitamin D Level and Risk of Community-Acquired Pneumonia and Sepsis. Nutrients 2014, 6, 2196-2205. [CrossRef]

33. Khalid, A.N.; Ladha, K.S.; Luong, A.U.; Quraishi, S.A. Association of Vitamin D Status and Acute Rhinosinusitis: Results From the United States National Health and Nutrition Examination Survey 2001-2006. Medicine 2015, 94, e1447. [CrossRef]

34. Monlezun, D.J.; Bittner, E.A.; Christopher, K.B.; Camargo, C.A.; Quraishi, S.A. Vitamin D Status and Acute Respiratory Infection: Cross Sectional Results from the United States National Health and Nutrition Examination Survey, 2001-2006. Nutrients 2015, 7, 1933-1944. [CrossRef] [PubMed]

35. Nanri, A.; Nakamoto, K.; Sakamoto, N.; Imai, T.; Akter, S.; Nonaka, D.; Mizoue, T. Association of serum 25-hydroxyvitamin D with influenza in case-control study nested in a cohort of Japanese employees. Clin. Nutr. 2017, 36, 1288-1293. [CrossRef] [PubMed]

36. Porojnicu, A.C.; Moroti-Constantinescu, R.; Laslau, A.; Lagunova, Z.; Dahlback, A.; Hristea, A.; Moan, J. Vitamin D status in healthy Romanian caregivers and risk of respiratory infections. Public Heal. Nutr. 2012, 15, 2157-2162. [CrossRef] [PubMed]

37. Quraishi, S.A.; Bittner, E.A.; Christopher, K.B.; Camargo, C.A. Vitamin D Status and Community-Acquired Pneumonia: Results from the Third National Health and Nutrition Examination Survey. PLoS ONE 2013, 8, e81120. [CrossRef] [PubMed]

38. Rafiq, R.; Thijs, W.; Prein, R.; De Jongh, R.T.; Taube, C.; Hiemstra, P.S.; De Mutsert, R.; Heijer, M.D. Associations of Serum 25(OH)D Concentrations with Lung Function, Airway Inflammation and Common Cold in the General Population. Nutrients 2018, 10, 35. [CrossRef] [PubMed]

39. Brance, M.L.; Miljevic, J.N.; Tizziani, R.; Taberna, M.E.; Grossi, G.P.; Toni, P.; Valentini, E.; Trepat, A.; Zaccardi, J.; Moro, J.; et al. Serum 25-hydroxyvitamin D levels in hospitalized adults with community-acquired pneumonia. J. Bone Min. Res. 2017, 32, S258. [CrossRef] [PubMed]

40. Holter, J.C.; Ueland, T.; Norseth, J.; Brunborg, C.; Frøland, S.S.; Husebye, E.; Aukrust, P.; Heggelund, L. Vitamin D Status and Long-Term Mortality in Community-Acquired Pneumonia: Secondary Data Analysis from a Prospective Cohort. PLoS ONE 2016, 11, e0158536. [CrossRef]

41. Kim, H.J.; Jang, J.G.; Hong, K.S.; Park, J.-K.; Choi, E.-Y. Relationship between serum vitamin D concentrations and clinical outcome of community-acquired pneumonia. Int. J. Tuberc. Lung Dis. 2015, 19, 729-734. [CrossRef]

42. Leow, L.; Simpson, T.; Cursons, R.; Karalus, N.; Hancox, R.J. Vitamin D, innate immunity and outcomes in community acquired pneumonia. Respirology (Carlton Vic.) 2011, 16, 611-616. [CrossRef] [PubMed]

43. Remmelts, H.; van de Garde, E.; Meijvis, S.; Peelen, E.; Damoiseaux, J.; Grutters, J.; Biesma, D.; Bos, W.J.; Rijkers, G. Vitamin D level predicts clinical outcome in community-acquired pneumonia. Eur. Respir. J. 2012, 40, 1361.

44. Yaghoobi, M.H.; Taher, A.; Seifrabie, M.A.; Sabahi, M.; Rahimi-Bashar, F. Serum vitamin D level was not associated with severity of ventilator associated pneumonia. Romanian J. Intern. Med. 2019, 57, 55-60. [CrossRef] [PubMed]

45. Mamani, M.; Muceli, N.; Basir, H.R.G.; Vasheghani, M.; Poorolajal, J. Association between serum concentration of 25-hydroxyvitamin D and community-acquired pneumonia: A case-control study. Int. J. Gen. Med. 2017, 10, 423-429. [CrossRef] [PubMed]

46. Robertsen, S.; Grimnes, G.; Melbye, H. Association between serum 25-hydroxyvitamin D concentration and symptoms of respiratory tract infection in a Norwegian population: The Tromso Study. Public Health Nutr. 2014, 17, 780-786. [CrossRef] [PubMed] 
47. Scullion, L.; Baker, D.; Healey, P.; Edwards, A.; Love, T.; Black, K. No Association between Vitamin D and Acute Respiratory Tract Infections Amongst Elite New Zealand Rugby Players and Rowers. Int. J. Vitam. Nutr. Res. 2018, 88, 8-15. [CrossRef] [PubMed]

48. Ginde, A.A.; Blatchford, P.; Breese, K.; Zarrabi, L.; Linnebur, S.A.; Wallace, J.I.; Schwartz, R.S. High-Dose Monthly Vitamin D for Prevention of Acute Respiratory Infection in Older Long-Term Care Residents: A Randomized Clinical Trial. J. Am. Geriatr. Soc. 2017, 65, 496-503. [CrossRef] [PubMed]

49. Majak, P.; Olszowiec-Chlebna, M.; Smejda, K.; Stelmach, I. Vitamin D supplementation in children may prevent asthma exacerbation triggered by acute respiratory infection. J. Allergy Clin. Immunol. 2011, 127, 1294-1296. [CrossRef] [PubMed]

50. Urashima, M.; Segawa, T.; Okazaki, M.; Kurihara, M.; Wada, Y.; Ida, H. Randomized trial of vitamin D supplementation to prevent seasonal influenza A in schoolchildren. Am. J. Clin. Nutr. 2010, 91, 1255-1260. [CrossRef]

51. Jorde, R.; Witham, M.; Janssens, W.; Rolighed, L.; Borchhardt, K.; de Boer, I.H.; Grimnes, G.; Hutchinson MSVitamin, D. Vitamin D supplementation did not prevent influenza-like illness as diagnosed retrospectively by questionnaires in subjects participating in randomized clinical trials. Scand. J. Infect. Dis 2012, 44, 126-132. [CrossRef]

52. Mattila, V.; Ylikomi, T.; Laaksi, I.; Ruohola, J.-P.; Auvinen, A.; Pihlajamäki, H. Vitamin D supplementation for the prevention of acute respiratory tract infection: A randomized, double-blinded trial among young Finnish men. J. Infect. Dis. 2010, 202, 809-814.

53. Li-Ng, M.; Aloia, J.F.; Pollack, S.; Cunha, B.A.; Mikhail, M.; Yeh, J.; Berbari, N. A randomized controlled trial of vitamin D3 supplementation for the prevention of symptomatic upper respiratory tract infections. Epidemiol. Infect. 2009, 137, 1396-1404. [CrossRef] [PubMed]

54. Manaseki-Holland, S.; Maroof, Z.; Bruce, J.; Mughal, M.Z.; Masher, M.I.; Bhutta, Z.A.; Walraven, G.; Chandramohan, D. Effect on the incidence of pneumonia of vitamin D supplementation by quarterly bolus dose to infants in Kabul: A randomised controlled superiority trial. Lancet 2012, 379, 1419-1427. [CrossRef]

(C) 2019 by the authors. Licensee MDPI, Basel, Switzerland. This article is an open access article distributed under the terms and conditions of the Creative Commons Attribution (CC BY) license (http://creativecommons.org/licenses/by/4.0/). 